\title{
Comparative Performance Modelling of Heat Pump based Heating Systems using Dynamic Carbon Intensity
}

\author{
Counsell .J. $^{1, a} \quad$ Khalid .Y. ${ }^{1, b} \quad$ Stewart .M. ${ }^{1, c}$ \\ ${ }^{1}$ Department of Electronic and Electrical Engineering, University of Chester, United Kingdom \\ aE-mail: j.counsell@chester.ac.ukbE-mail: y.khalid@chester.ac.ukcE-mail:m.stewart@chester.ac.uk
}

\begin{abstract}
Modern buildings and homes utilise multiple systems for energy generation, supply and storage in order to maintain occupant comfort, reduce operating costs and $\mathrm{CO}_{2}$ emissions. In recent times electricity generation and supply network (UK National Grid) have had to manage variable supply from renewable sources such as wind turbines and photovoltaics. This resulting supply mixture has a dynamic profile at intermittent times. To manage excess supply, the options are either to reduce the generation by power stations/renewables or reinforce the power infrastructure with storage capability. This has given rise to calls for electrification of services in streamlining the supply profile through intelligent demand response such as electric heating and vehicles. Furthermore, due to zero carbon energy sources with dynamic supply profile, the carbon intensity is no longer constant. This impacts the seasonal $\mathrm{CO}_{2}$ emissions calculations and also the design and performance of electrical powered heat pump based heating systems.
\end{abstract}

The RISE (Renewable Integrated Sustainable Electric) heating system was developed (funded by the UK Research and Innovation), where an electrical powered Heat pump is combined with electric thermal storage allowing low cost and low carbon electricity to be utilised. For such a system more realistic performance analysis requires dynamic carbon intensity calculations to assess impact on its ability to maintain comfort, low operating costs and low carbon emissions. The paper builds upon previously published research on the RISE system comparing with domestic Gas Condensing Boiler (GCB) using static carbon calculations.

This paper presents a comparison between the RISE system and standard domestic electrical powered Air Source Heat Pump (ASHP) when using static and dynamic carbon intensity profiles. The Inverse Dynamics based Energy Assessment and Simulation (IDEAS) framework is utilised for modelling and dynamic simulation of building and heating system, operating cost and estimation of annual emissions based on half hourly (HH) dynamic $\mathrm{CO}_{2}$ intensity figures rather than annual average.

The results show that with dynamic carbon intensity calculations, both electric heat pump based heating systems, RISE and ASHP show a significant increase $(>15 \%)$ in carbon emissions for space heating. The results also show that whilst the RISE system's thermal storage helps to reduce running costs using a time of use tariff (TOU), it only provides a small benefit in carbon emissions.

Keywords- Dynamic Carbon intensity $\left(\mathrm{CO}_{2}\right)$, renewable power generation, Air Source Heat Pumps (ASHP), electric thermal storage, Gas Condensing Boiler (GCB)

I. INTRODUCTION
In the UK, space heating, cooling and hot water in buildings accounts for half of UK's energy consumption. Decarbonisation of heat in the domestic sector could significantly contribute to the UK carbon emissions reduction target of $80 \%$ by 2050 relative to 1990 levels [1] Major portion of current heat supply to the domestic sector is through natural gas and the rest by electricity. In the UK, Low carbon electric heating has been identified as an important innovation for reducing carbon emissions [1-3].

Electric Air Source Heat Pumps are one of the technologies identified as having potential for decarbonisation of heat [16]. Their performance however, (i.e. Seasonal Performance Factor (SPF)) degrades at low operating temperatures making them more expensive to run and more carbon intensive $[4,15]$. Hence there is a need in winter for additional cost effective low carbon heat source that can top-up when required without driving the heat pump into inefficient regions of operation. In addition with the widespread electrification of heating via heat pumps would add significant pressure on electrical infrastructure, in particular an increase of peak demand at winter evening peak times when the network is usually under greatest stress.

The design of the UK's future framework for heat in buildings has to take account of the following factors [3]:
a) Renewable Integrated energy supply
b) Reinforcement of electricity network
c) Storage capability for excess energy
d) Energy efficient electric heating
e) Competitive with gas heating systems

To this effect, Hybrid Heat Pumps (HHP) solutions are being investigated such as:

1. HHP with Gas Condensing Boilers [1]

2. HHP with Electric Thermal Storage [4]

In this paper using modelling and simulation the performance of HHP with Electric Thermal storage is compared with a standard domestic Electric Air source Heat Pump (ASHP).

\section{HyBRID ElECTRIC HEAT PUMP SYSTEM}

Currently UK investment is supporting all electric hybrid heating system solutions utilising off-peak electricity and 
with heat pumps supplying heat to micro heat networks, hence reducing the pressure on the Gas Grid [3]. The above low carbon electricity philosophy has been applied to innovate a hybrid heating solution (RISE) that utilises electric driven air source heat pumps (ASHP) with offpeak electric powered thermal storage (Quantum Boiler $\mathrm{QB}$ ) [4]. Figure 1 (below) shows the RISE system configuration for multi-dwelling units (MDU) as an affordable low carbon and secure heating solution for social housing in the UK.

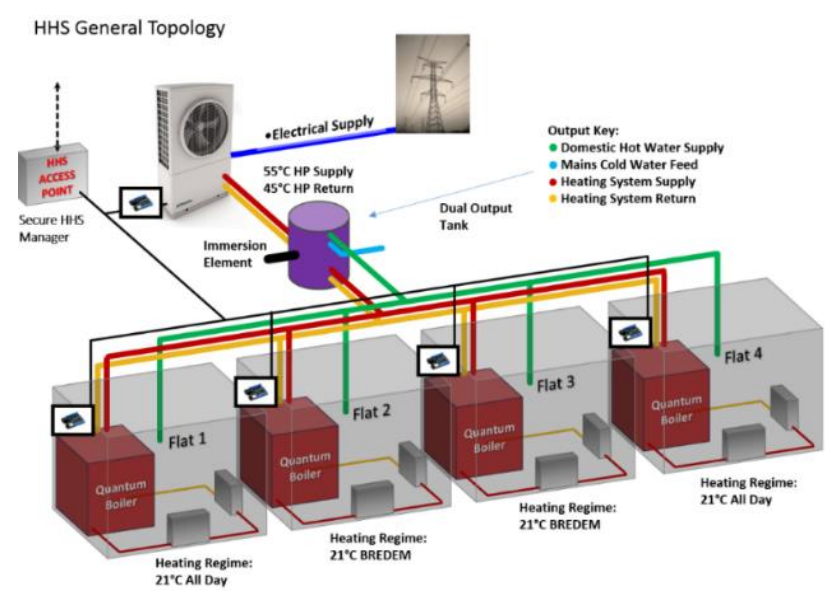

Fig. 1: Schematic of RISE system [4]

Initial live prototype trials [4] and dynamic simulations of such system type have shown great potential for reducing emissions, energy and costs that could compete with domestic Gas Condensing Boiler and Electric Air Source Heat Pump using static carbon intensity [5].

Table 1: System Performance Comparison

\begin{tabular}{cccc}
\hline $\begin{array}{c}\text { Heating } \\
\text { System }\end{array}$ & $\begin{array}{c}\text { Cost } \\
(£ / \mathrm{yr})\end{array}$ & $\begin{array}{c}\text { Heat } \\
(\mathrm{kWh} / \mathrm{yr})\end{array}$ & $\begin{array}{c}\mathrm{CO}_{2} \\
(\mathrm{~kg} / \mathrm{yr})\end{array}$ \\
\hline ASHP (E7) & 1126.8 & 21998.7 & 3301.0 \\
RISE (E7) & 852.9 & 22398.0 & 3337.3 \\
RISE (TOU) & 765.4 & 22398.0 & 3337.3 \\
GCB & 834.7 & 21965.0 & 4041.6 \\
\hline
\end{tabular}

Where:

GCB efficiency $=0.929$

RISE SPF $=3.04$ ASHP SPF $=3$

E7=Economy 7 Tariff

TOU=Time of Use Tariff

Static Carbon Intensity $=0.447$

\section{Modelling, Simulation AND CONTROL}

The IDEAS modelling and simulation framework was used that enables multi-vector modelling and intelligent controller design in a single holistic method. It allows energy system designers to assess dynamic control of building systems while simulating minute by minute energy, cost and carbon emissions for the whole year with dynamic weather data, fuel tariffs and carbon intensity [6].
The RISE system configuration for the trials and modelling, simulation and control of ASHP, QB and thermal tank are detailed in the previously published research [4]. The measured data from live prototype trails was used to calibrate the dynamic model and control system for performance analysis. The RISE system was scheduled in prototype trials and simulation shown in table below. In the simulation, the supplying of heat was switched between operating ASHP and QB based electricity tariff for utilising off peak electricity [4].

Table 2: RISE system operational schedule

\begin{tabular}{cc}
\hline $\begin{array}{c}\text { ASHP time } \\
\text { Clock } \\
\text { Mon-Sun }\end{array}$ & $\begin{array}{c}\text { QB Time clock } \\
\text { Mon-Sun }\end{array}$ \\
& $\begin{array}{c}\text { EIC - Electric Input Charging } \\
\text { HOF - Heat Output Fan }\end{array}$ \\
\hline 05:30 On & 03:00-07:00 EIC on, HOF off \\
07:00 Off & 07:00 EIC off, HOF on \\
14:30 On & 09:00 EIC off, HOF off \\
16:00 Off & 16:00 EIC off, HOF on \\
20:00 On & 20:00 EIC off, HOF off \\
22:00 Off & 20:00-03:00 EIC off, HOP off \\
\hline
\end{tabular}

Table 3: Energy Tariffs compared ( $\mathrm{p} / \mathrm{kWh}$ )

\begin{tabular}{ccc}
\hline Times & E7 (p/kWh) & TOU $(p / k W h)$ \\
\hline 00:00-00:30 & 7.6 & 7 \\
00:30-04:30 & 7.6 & 7 \\
04:30-07:00 & 14.37 & 12.7 \\
07:00-13:30 & 14.37 & 12.7 \\
13:30-16:00 & 14.37 & 12.7 \\
06:00-20:00 & 14.37 & 25 \\
20:00-23:00 & 14.37 & 12.7 \\
23:00-00:00 & 7.6 & 7 \\
\hline
\end{tabular}

In this paper, for the same system schedule running on E7 \& TOU tariffs, the calibrated model $[4,6,13]$ of the RISE heating system is used to analyse its performance in terms of the current dynamic state of UK power grid caused by renewable power generation resulting in dynamic carbon intensity for realistic Green House Gas (GHG) Emissions.

\section{CARBON INTENSITY}

Emission conversion factor (ECF) is a general term used to compare the environmental impact of different fuels or activities or sectors in terms of pollutants emitted. The term which is used to compare emissions from different sources of electrical power is called the carbon intensity in which only $\mathrm{CO}_{2}$ emissions are considered and other pollutants are excluded. Carbon intensity of electricity is a measure of how much $\mathrm{CO}_{2}$ emissions are produced per kWh of electricity consumed.

Globally, current practice is to use static carbon intensity figures (i.e. same $\mathrm{kg} / \mathrm{kWh}$ of electricity at all times) to calculate the total $\mathrm{CO}_{2}$ emissions [14]. In the UK, the government department of Business Energy and Industrial Strategy (BEIS) publishes the carbon intensity 
figures [7] which are utilised in the building regulations calculations for energy compliance in building projects.

Ideally in building regulations, the static carbon intensity should be replaced with seasonally dynamic carbon intensity. This is important for UK power sector as the continued deployment of intermittent renewables has altered the static nature of energy supply and demand network, raising challenges related to investments in grid infrastructure and generation capacity.

A robust methodology for calculation of $\mathrm{CO}_{2}$ emissions is critical to implementation of UK government carbon emissions reductions policies as well as performance assessment of different service technologies. In the UK, the basis for emissions calculations is the type and source of fuel and the efficiency of the fuel conversion process. In the case of natural gas fueled systems, a constant $\mathrm{CO}_{2}$ intensity value (usually given in $\mathrm{kgCO}_{2} / \mathrm{kWh}$ ) is accepted as a reasonably accurate approximation aggregated and averaged from the UK's multiple gas supply sources, gas flow moisture content, network churn and other factors.

Similarly, the carbon intensity of electricity is given as an annual average calculated from fractional contribution to total supply by each generating plant type, otherwise known as the fuel mix. In the electricity calculation and reporting framework, variations in $\mathrm{CO}_{2}$ intensity within each plant type are averaged across the fleet. For example, all combined cycle gas turbine (CCGT) plants are assumed to produce $\mathrm{CO}_{2}$ at a rate of $0.38 \mathrm{~kg}$ per $\mathrm{kWh}$ generated (2018 value) irrespective of particular station age, actual plant utilisation or technology variations within the category. Other generator types and operation are averaged and aggregated in the same way.

This general methodology and approach provides sufficient insight for current policy purposes relating to emissions from large scale electricity generation and gives a crude method for technology assessment. This method is, however, critically predicated on assuming one side of the equation being static. For example, the ubiquitous domestic gas condensing boiler has a diurnal and seasonal operational profile but its emissions can be represented with reasonable accuracy since the $\mathrm{CO}_{2}$ intensity of network supplied natural gas does not vary much by time of day or by season and can thus be taken as a constant value.

The same cannot be said for electrically driven appliances whose operational profile is also diurnal and seasonal but whose $\mathrm{CO}_{2}$ attributes are variable and dominated by peak daily and winter fuel mix intensities. These intensities are usually higher than the annual average and much higher than night-time and summer intensities. This discrepancy results in a skewed representation of emissions performance and produces an unfair bias in favour of certain electric heating systems in terms of technology assessment. Heat pumps fall into this category.
This paper reports emissions performance of 2 electric heating systems in 2 scenarios to illustrate and compare a static $\mathrm{CO}_{2}$ emissions intensity versus a dynamic intensity profile which is arguably closer to the reality:

1. An air-source heat pump system using conventional static carbon value against the same system using a dynamic representation of emissions intensity

2. A hybrid heating system featuring air source heat pump with integrated electric boiler in static emissions intensity mode versus the same system in dynamic emissions intensity mode.

Both of these systems are implemented in the IDEAS dynamic modelling and simulation framework to compare performance using Matlab/Simulink. This framework has previously been validated against SAP and has also modelled clusters of mixed building types [4 \& 6].

$$
\text { V. UK FUEL MIX AND } \mathrm{CO}_{2} \text { INTENSITY }
$$

The UK's generating plant mix is undergoing a period of transition to meet carbon emissions reduction policy objectives. Data from OFGEM indicates renewable capacity has trebled since 2010 with solar PV now accounting for $12 \mathrm{GWp}$ installed base and wind a further 20GWp. Electricity from all fossil fuel sources is down $44 \%$ since 2010 primarily due to shift away from coal based generation [8]. Carbon intensities of each generator type used in this study are given by the Fuel Mix Disclosure policy administered by BEIS [9].

These static values are reproduced for 2017 in Table 4.

Table 4: GB Generating Plant Emissions Intensity Values \& Fraction of Annual Supply [9]

\begin{tabular}{ccc}
\hline $\begin{array}{c}\text { Carbon Intensities } \\
\text { of Generating plant }\end{array}$ & $\mathrm{kgCO}_{2} \mathrm{e} / \mathrm{kWh}$ & \%Contribution \\
\hline CCGT & 0.378 & $40.1 \%$ \\
OIL & 0.616 & $0.0 \%$ \\
COAL & 0.931 & $6.3 \%$ \\
NUCLEAR & 0 & $23.9 \%$ \\
WIND & 0 & $11.6 \%$ \\
SOLAR PV & 0 & $3.4 \%$ \\
PS & 0 & $0.9 \%$ \\
NPSHYD & 0 & $1.3 \%$ \\
OCGT & 0.488 & $0.0 \%$ \\
OTHER & 0.639 & $4.4 \%$ \\
FRENCH & 0.09 & $3.8 \%$ \\
IRISH & 0.45 & $0.4 \%$ \\
DUTCH & 0.55 & $2.5 \%$ \\
EW & 0.45 & $0.6 \%$ \\
BIOMASS & 0.639 & $0.7 \%$ \\
\hline
\end{tabular}

Figure 2 below illustrates the trends in GB fuel mix for primary generating categories. 


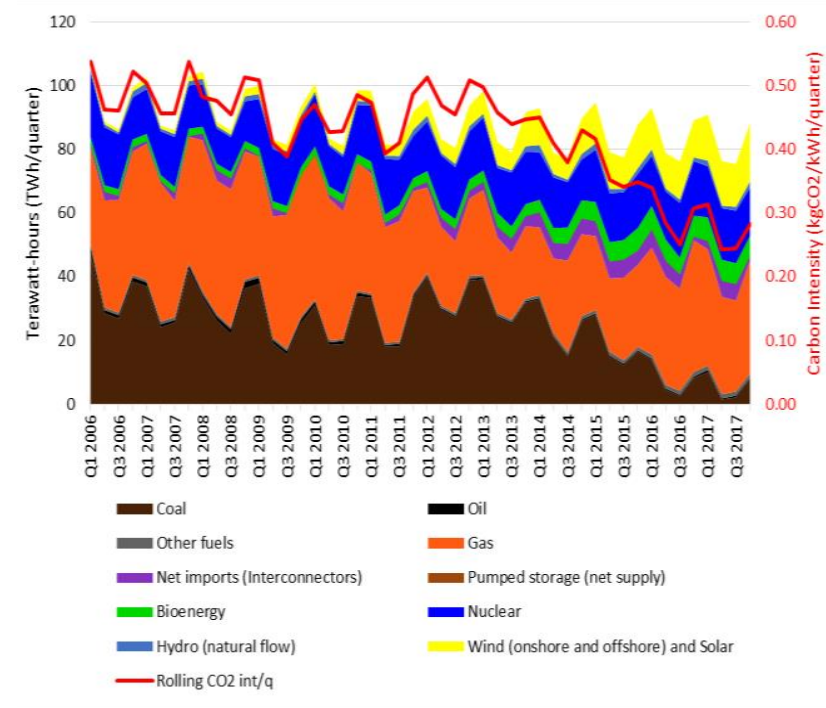

Fig. 2: Trends in GB Electricity Generating Fuel Mix [8]

Of note in Figure 2 is increased use of natural gas for electricity generation since 2012 , now contributing over $40 \%$ to the mix. The 2017 (OFGEM) annual average carbon intensity using this dataset was $0.28 \mathrm{kgCO}_{2} / \mathrm{kWh}$.

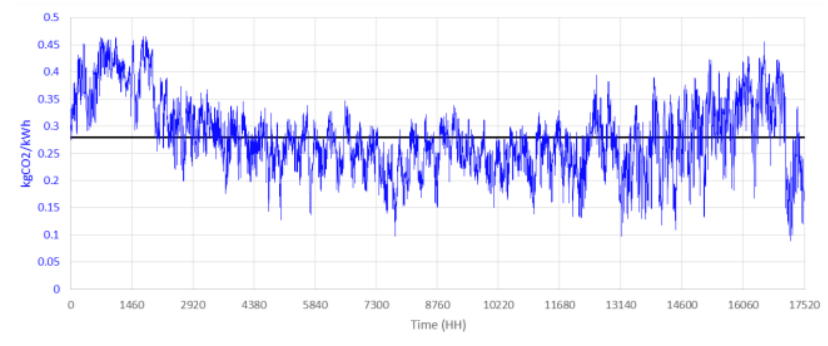

Fig. 3: Half Hourly (HH) Carbon Intensity of GB Electricity Supply (2017)

Using HH fuel mix data from Elexon [10] and weighting by generator emissions intensity as given by BEIS results in the profile shown in Figure 3. The figure also shows the static annual average value for comparison. Clearly from figure 3 , emissions are actually greater than average during winter and also at daily peak load times as is seen in figure 2 . The minimum value in the Figure $3 \mathrm{HH}$ dataset is $0.09 \mathrm{kgCO}_{2} / \mathrm{kWh}$ registered for 1 hour each at $2 \mathrm{pm}$ June 6th and midnight on Sunday October 1st.

\section{DYNAMIC $\mathrm{CO}_{2}$ INTENSITY}

The Green House Gas Emissions (GHG) with static carbon intensity $(\mathrm{Cl})$, are calculated as follows:

\section{GHG Emissions = Energy consumed $\times \mathrm{Cl}$}

Where:

GHG Emissions = Green House Gas Emissions (kg)

Energy Consumed $=$ Total energy consumed every $1 / 2$ hour in the whole year $(\mathrm{kWh})$

$\mathrm{Cl}=$ Carbon Intensity Factor $\left(\mathrm{kg} \mathrm{CO}{ }_{2} \mathrm{e} / \mathrm{kWh}\right)$
For a dynamic carbon analysis the $\mathrm{Cl}$ is created as a dynamic input profile to the IDEAS model which changes throughout the year based on the electricity generation mix.

The $\mathrm{Cl}$ profile is created based on the fuel mix of the UK electricity generation. There is no official test reference fuel mix data set for a study of this kind therefore the last full year (2017) of fuel mix data was used. This data is available from Elexon [10] and National Grid [11] whose remit includes reporting such data for market and operational transparency purposes. These datasets are collated and used by other government agencies such as OFGEM [8] and reported annually in publications such as DUKES [12].

The simple method developed in this paper to derive a dynamic $\mathrm{CO}_{2}$ profile uses fuel mix as reported by Elexon at $\mathrm{HH}$ intervals weighted by an average annual carbon intensity value ascribed to each generator type from data published by BEIS [9].

The $\mathrm{HH}$ intensity profile dataset was used in the simulation as a gain against electricity demand to generate $\mathrm{CO}_{2}$ emissions dynamically. The average of this dynamic intensity profile was also used in the Matlab model as the annual static intensity value to give comparative results for both scenarios.

The model parameter configuration was implemented in Matlab with the dynamic models in Simulink. The dynamic $\mathrm{CO}_{2}$ profile was implemented in Simulink as the input signal to an appliance ' $\mathrm{CO}_{2}$ meter' shown in Figure 4.

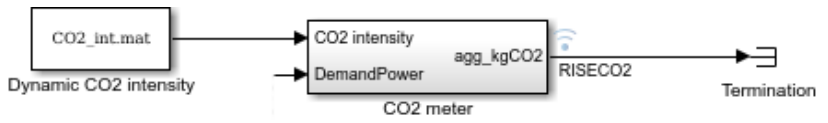

Fig. 4: Simulink CO2 meter model block

Mathematically, this block simply integrates an intensity value multiplied by appliance power. Where $\mathrm{CO}_{2}(\mathrm{t})$ is the total emissions at each time-step, $\mathrm{Cl}(\mathrm{t})$ is emissions intensity at time $(t)$ and $E_{\text {power }}(t)$ is appliance electrical demand at time $(\mathrm{t})$.

$$
\mathrm{CO}_{2}(t)=\int_{0}^{t} C I(t) \times E_{\text {power }}(t)
$$

\section{DYNAMIC CARBON RESULTS}

Relevant test results were collated and compared for both systems in both scenarios. The plots in Figure 5 show ASHP model resultant Air temperatures for weeks 2, 14, 26 and 38 respectively (winter, spring, summer, and autumn). 

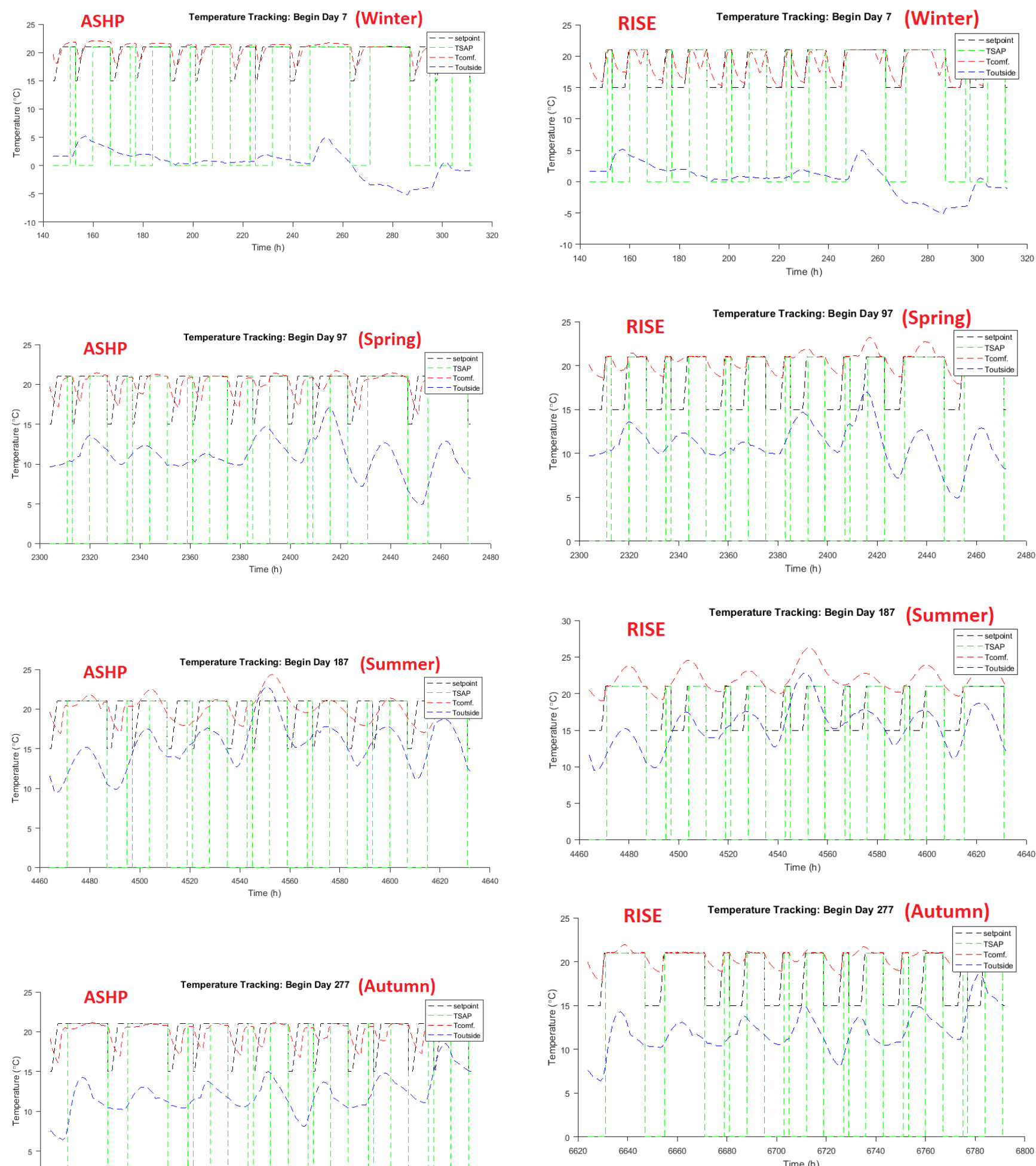

Fig. 6: RISE Model Resultant Air Temperature

Similarly, the plots in Figure 6 show RISE model resultant Fig. 5: ASHP Model Resultant Air Temperature Air temperatures for weeks 2, 14, 26 and 38 respectively.

The plots in Figure 7 detail RISE system heat flows (heat pump, boiler) for weeks 2, 14, 26 and 38 respectively. 

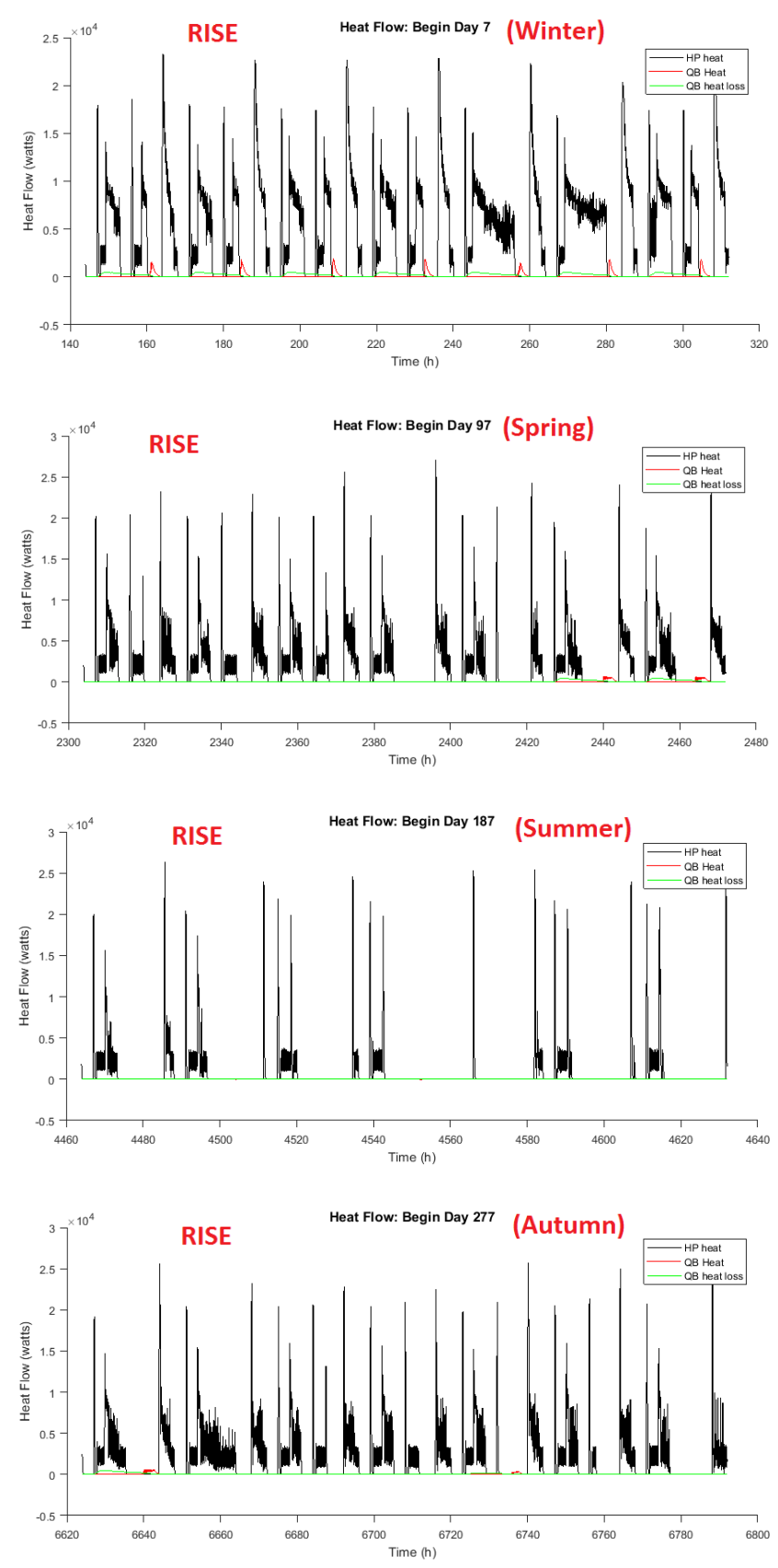

Fig. 7: RISE Model Resultant Heat Flows

Table 5 Collates and presents annual values from the dynamic results.

Table 5: System Performance Comparison

\begin{tabular}{cccc}
\hline & Units & ASHP & RISE \\
\hline Total Running cost & $f / y r$ & 886.80 & 852.87 \\
Electricity demand & $\mathrm{kWhe} / \mathrm{yr}$ & 7334.1 & 7446.0 \\
System SPF & Ratio & 3.0054 & 3.0394 \\
Emissions (Static) & $\mathrm{kg} / \mathrm{yr}$ & 1982.9 & 2015.8 \\
Emissions (Dynamic) & $\mathrm{Kg} / \mathrm{yr}$ & 2319.2 & 2325.3 \\
$\Delta \mathrm{CO}_{2}$ & ratio & $17 \%$ & $15.4 \%$ \\
\hline
\end{tabular}

\section{DISCUSSION AND CONCLUSIONS}

In this paper, the Inverse Dynamics based Energy Assessment and Simulation (IDEAS) framework is utilised for modelling and simulation of building and heating system, operating cost and estimation of annual emissions based on half hourly dynamic $\mathrm{CO}_{2}$ intensity figures rather than annual average. This paper builds upon previous research and development in hybrid heat pumps by adding the dynamic carbon vector to the analysis. This work has allowed for more realistic performance analysis of hybrid heating systems where hourly electricity generation mix composition changes the carbon intensity of the supplied electricity. The results of this research show that by applying dynamic carbon intensity on a $1 / 2$ hourly basis can make the comparative performance analysis of hybrid heat pumps more carbon competitive with current UK gas heating and standalone heat pump systems. The demand for sustainable housing is increasing in UK, and the need for heating systems which can ease the pressure on grid infrastructure and generate capacity as well as satisfy the energy trilemma hold true potential for social economic impact. Therefore, calculation methods for comparisons, impact and scenario analysis have to reflect the changing reality.

Both simulations produced plausible results for space heating with the setpoint being better tracked in the RISE system due to use of a thermal store. This performance boost over a standard ASHP is a feature of RISE. In terms of operating cost and $\mathrm{kWh} / \mathrm{pa}$ demand, both systems are similar with RISE having a slight edge in cost per kWh. This is due to the off-peak capabilities of the thermal store in RISE. Both the ASHP and the RISE system achieve a SPF of 3.

The static intensity baseline scenario also produced similar results for both cases. However, and as stated in the abstract, $\mathrm{CO}_{2}$ emissions based in $\mathrm{HH}$ fuel mix were higher for both systems ( $17 \%$ and $15 \%$ respectively) than are suggested using a static intensity profile, hence going some way to justifying the statement suggesting bias in the current emissions reporting methodology and performance assessment framework for electric appliances. There is a significant bias in the way in which emissions are calculated for certain appliances. This bias will always exist given its nature. In this paper, this bias was shown through dynamic simulation and comparison of emissions using a static intensity value versus a dynamic value for two heat pump based systems in a poor-insulated house.

The benefits of RISE over a standard ASHP installation are also apparent. In general, these benefits could also extend to other electric heating systems with integrated energy storage and unified control strategy. Table 5 clearly shows at least a $15 \%$ increase in carbon emissions for electric space heating when using a dynamic carbon calculation than when using a year average static carbon figure. This is primarily as a result of the highest carbon emission electricity being generated in winter months when electric heating appliances have their highest demand. So it is vitally important that dynamic carbon is used to reflect the true carbon emissions of electric based 
heating solutions. The use of a small amount of thermal storage in the RISE heating system has a $2 \%$ benefit in preventing increased carbon emissions when moving from static to dynamic carbon calculation method. Thus, the carbon benefit of thermal storage in the RISE system is less significant than the running cost benefit using Time of Use tariffs as previously studied [4].

\section{ACKNOWLEDGMENTS}

The Authors gratefully acknowledge EPSRC funding for this paper through the Heat-STRESS project in collaboration with Newcastle University.

\section{REFERENCES}

[1] Element Energy Ltd (2017). Hybrid Heat Pumps, Final Report for BEIS (Department of Business, Energy \& Industrial Strategy), UK Government.

[2] BEIS, (2018). Policy Paper: Clean Growth Strategy, Department for Business, Energy and Industrial Strategy (BEIS), UK Government.

[3] BEIS, (2018). A Future framework for heat in buildings, Department for Business, Energy and Industrial Strategy (BEIS), UK Government.

[4] Counsell, J.; Khalid, Y.; Stewart, M. (2017), 'Hybrid Heat Pump for Micro Heat Network', World Academy of Science, Engineering and Technology, International Science Index 127, International Journal of Electrical, Computer, Energetic, Electronic and Communication Engineering, 11(7), 927 - 936.

[5] Counsell, J.; Khalid, Y.; Final project report (2017), RISE project (Innovate UK) University of Chester.

[6] Stewart, M. ; Al-Khaykan, A. ; Counsell, J. (2017), 'Assessment of Multi-Domain Energy Systems Modelling Methods', World Academy of Science, Engineering and Technology, International Journal of Energy and Power Engineering Vol:11, No:7, 2017

[7] Greenhouse gas reporting: conversion factors (2018) https://www.gov.uk/government/publications/greenhouse -gas-reporting-conversion-factors-2018

[8] Ofgem (2018) Historic Quarterly Fuel Mix, online resource, https://www.ofgem.gov.uk/data-portal/electricitygeneration-mix-quarter-and-fuel-source-gb

[9] BEIS (2018) Fuel Mix Disclosure Data Table 2018, https://assets.publishing.service.gov.uk/government/uploa ds/system/uploads/attachment_data/file/730967/fuelmix-disclosure-data-2018.pdf

[10] Balancing Mechanism Reporting Service, online resource, https://www.bmreports.com/bmrs/?q=help/about-us

[11] Operating Conditions Data Explorer, online resource, https://www.nationalgrid.com/uk/electricity

[12] Digest of UK Energy Statistics, 2018, online resource, https://www.gov.uk/government/statistics/digest-of-ukenergy-statistics-dukes-2018-main-report

[13] Murphy, G.B., Counsell, J.M., et al "Calibrating a combined energy systems analysis and controller design method with empirical data", Elsevier journal "Energy", Vol 57, pp484494, August 2013

[14] Evens, B.; Sidat, S. (2017), 'An investigation into the use of temporal factors for $\mathrm{CO} 2$ emissions accounting in buildings', CIBSE ASHRAE Technical Symposium, Loughborough, UK 56 April 2017

[15] A. Hakkaki-Fard et al. (2015), "Improving cold climate air source heat pump performance with refrigerant mixtures"
Applied Thermal Engineering, Volume 78, 5 March 2015, Pages 695-703

[16] Customer-Led Network Revolution (2015), Insight Report: Domestic Heat Pumps. CLNR-L091 Durham Energy Institute and Element Energy: 23rd January 2015. 